\title{
Retrieval of Martian ozone and dust from SPICAM spectrometer for MY27-MY28
}

\author{
Ashimananda Modak ${ }^{1}$, VArun SheEL $^{1, *}$ (D) and FrancK Montmessin ${ }^{2}$ \\ ${ }^{1}$ Physical Research Laboratory, Navrangpura, Ahmedabad 380009, India. \\ ${ }^{2}$ Laboratoire Atmosphères, Milieux, Observations Spatiales (LATMOS), Guyancourt, France. \\ *Corresponding author.e-mail: varun@prl.res.in
}

MS received 22 August 2018; revised 1 January 2019; accepted 14 January 2019; published online 31 May 2019

Ozone $\left(\mathrm{O}_{3}\right)$ is important in the stabilisation of $\mathrm{CO}_{2}$ in the Martian atmosphere and thus it is important to study the spatio-temporal variability of $\mathrm{O}_{3}$. We retrieve two years of total columnar $\mathrm{O}_{3}$ from raw spectral data provided by the SPectroscopy for the Investigation of the Characteristics of the Atmosphere of Mars (SPICAM) instrument aboard the Mars Express. The seasonal variability is studied in tropical, mid- and high latitudes and is compared with simulations by a photochemical coupled general circulation model (GCM). The high latitudes exhibit the largest seasonal variations in $\mathrm{O}_{3}$, with a winter high and a summer low and a comparison with GCM results is good in general. We have studied the correlation of $\mathrm{O}_{3}$ with dust, retrieved simultaneously from SPICAM observations. In southern tropical latitudes, the columnar $\mathrm{O}_{3}$ is seen to increase during a global dust storm year (Martian year (MY) 28) compared to the $\mathrm{O}_{3}$ column values during a year without global dust storm (MY27), although the water vapour column between these years remains unchanged. This indicates the radiative impact of dust on $\mathrm{O}_{3}$ and its retrieval. We also study the ozone-carbon monoxide correlation as a tracer of dynamics. The dynamical contribution to the $\mathrm{O}_{3}$ column is found to be the highest during winter over the southern polar region.

Keywords. Ozone-dust correlation; retrieval of ozone; $\mathrm{O}_{3}-\mathrm{CO}$ correlation; SPICAM; Martian ozone.

\section{Introduction}

Stability and composition of the Martian atmosphere are controlled by photochemical processes (Krasnopolsky 2006), of which ozone $\left(\mathrm{O}_{3}\right)$ is one of the most active species. Hydroxyl ions $(\mathrm{OH})$, which are a sink for $\mathrm{O}_{3}$ and carbon monoxide (CO), have not been extensively observed on Mars. Thus, $\mathrm{O}_{3}$ and $\mathrm{CO}$ and their correlation have become important options for use as tracers for $\mathrm{OH} . \mathrm{O}_{3}$ is also important in determining the habitability of Mars, as it modulates the surface ultraviolet (UV) flux. It was detected for the first time by the absorptions of the Hartley band in the UV and the IR features by the UV spectrometer aboard
Mariner 7 flyby (Barth and Hord 1971). Since then, there have been many Earth- and space-based remote-sensing observations which have explored $\mathrm{O}_{3}$ in the Martian atmosphere. To mention a few: The UV spectrometer aboard Mariner 9 (Barth et al. 1973), spectroscopy for the investigation of the characteristics of the atmosphere of Mars (SPICAM) aboard the Mars Express (Perrier et al. 2006) and MARs Colour Imager (MARCI) (Clancy et al. 2016) aboard the Mars Reconnaissance Orbiter (MRO). Ground-based studies such as the heterodyne instrument for planetary wind and composition (HIPWAC) (Fast et al. 2009) of the NASA Goddard Space Flight Center InfraRed Heterodyne Spectrometer (IRHS) (Fast et al. 2006), 
the hubble space telescope faint object spectrograph (Clancy et al. 1996) and a highresolution infrared telescope (CSHELL) at the NASA infrared telescope facility (Novak et al. 2002) provided significant insight into Martian $\mathrm{O}_{3}$. These observations have improved our knowledge about the seasonal and temporal variations of $\mathrm{O}_{3}$.

The global distribution of $\mathrm{O}_{3}$ (longitudinal averaged) is reported from remote-sensing observations by Perrier et al. (2006) and Clancy et al. (2016). In recent years, vertical profiles of $\mathrm{O}_{3}$ measured using a SPICAM UV spectrometer have shown the presence of two distinct $\mathrm{O}_{3}$ layers at lowto-mid latitudes (Lebonnois et al. 2006). The first peak occurs near the surface and the second nocturnal peak between 25 and $60 \mathrm{~km}$ was detected for the first time by solar occultation observations from Phobos (Blamont and Chassefiere 1993). Based on the stellar occultation measurements by SPICAM, Montmessin and Lefèvre (2013) reported a third layer of $\mathrm{O}_{3}$ over the winter south pole between 35 and $70 \mathrm{~km}$ with a peak at about 50 $\mathrm{km}$. This layer has been attributed to the cross equatorial Hadley cell in which warmer air rises and travels poleward before cooling and sinking at higher latitudes. The deep downwelling air is rich in oxygen molecules, which recombine in the polar night to form $\mathrm{O}_{3} \cdot \mathrm{O}_{3}$ can also be affected by the topography of Mars, through the effect of gravity waves. An increase in $\mathrm{O}_{3}$ column over Hellas basin is attributed to a topographically induced transport of the polar night air, enriched in $\mathrm{O}_{3}$ (Clancy et al. 2016).

These studies lead us to believe that there should be an anti-correlation of $\mathrm{O}_{3}$ with water vapour (Lefèvre et al. 2004; Fast et al. 2006; Fedorova et al. 2006; Clancy et al. 2016; Willame et al. 2017). This anti-correlation was inferred for the first time from Mariner 9 observations (Barth et al. 1973). The photolysis of water vapour provides odd hydrogen radicals $\left(\mathrm{HO}_{x}\right)$ which are responsible for the catalytic loss of $\mathrm{O}_{3}$ (Nair et al. 1994). Both polar caps and the regolith trap water vapour when the temperature is low. The northern polar cap is a greater source of water vapour compared to the southern polar cap. The atmosphere over other regions of Mars contains comparatively less water vapour. $\mathrm{O}_{3}$ is mainly produced in the sunlit latitudes where oxygen atoms are abundant due to the dissociation of $\mathrm{CO}_{2}$ and $\mathrm{O}_{2}$ and combine with $\mathrm{O}_{2}$ to produce $\mathrm{O}_{3}$. During winter over polar-regions, the contribution to the $\mathrm{O}_{3}$ column comes mainly from the transport of $\mathrm{O}_{3}$ from sunlit latitudes. During summer, polar caps release water vapour and destroy the $\mathrm{O}_{3}$ column. However, it is believed that the degree of anti-correlation varies from region to region (Lefèvre et al. 2004). Latitudinal and seasonal variations in the temperature of the Martian atmosphere control the water vapour saturation level (hygropause) and thus the $\mathrm{O}_{3}$ distribution. Thus, e.g., during the spring and fall when the temperatures are low, high $\mathrm{O}_{3}$ is observed in the mid-to-high latitudes. As a result of the anti-correlation with water vapour, $\mathrm{O}_{3}$ is at the maximum during winter and at the minimum during summer in general for all latitudes (Barth et al. 1973). It is our aim to study the seasonal and meridional variation of $\mathrm{O}_{3}$ using observations from remote sensing and simulations from a model.

Dust aerosol is the most important component of Martian meteorology. Dust affects the incoming and outgoing solar radiation by its radiative properties. It heats up by absorbing in the visible region of the solar spectrum and cools down by radiating in the infrared region, thus modifying the temperature profile (Gierasch and Goody 1972; Zurek 1978). Daytime absorption of solar radiation lifts dust to a height $20-30 \mathrm{~km}$ above the surface (Guzewich et al. 2013). The Martian atmosphere is characterised by global dust storms, regional dust storms and local dust storms (Martin and Zurek 1993; Smith 2009; Sheel and Haider 2016). These dust events change the vertical profile of dust (Heavens et al. 2011). Dust optical depth varies seasonally and also with the global and regional storms (Sheel and Haider 2016). The annual variation of these storms is not fully known. As the optical depth increases, solar radiation cannot penetrate deeper. This reduces the availability of solar radiation at many layers of the atmosphere and thus affects the photochemistry of Mars. In this study, we will retrieve the optical depths of dust along with the $\mathrm{O}_{3}$ column for various latitude regions and for various seasons.

$\mathrm{O}_{3}$ in the atmosphere of Mars is closely linked to $\mathrm{CO}$ (produced by the photodissociation of $\mathrm{CO}_{2}$ and is mainly destroyed by oxidation with $\mathrm{OH}$ radicals). CO can be used as a dynamical tracer in the Martian atmosphere because of its longer lifetime (González-Galindo et al. 2005), and as shown by Clancy et al. (2016) has been used to determine the increase of $\mathrm{O}_{3}$ in the Hellas basin. In this study, we will, therefore, also examine the variability of the $\mathrm{CO}-\mathrm{O}_{3}$ correlation in the Martian atmosphere. 


\section{Objective}

The observations of $\mathrm{O}_{3}$ on Mars are important not only because of their importance in photochemistry, but also to test photochemistry-coupled general circulation models (GCMs) which simulate the spatio-temporal variation of $\mathrm{O}_{3}$ and related species. Also, the variations in the UV environment of Mars are mainly due to $\mathrm{O}_{3}$ and dust. $\mathrm{O}_{3}$ strongly absorbs $\mathrm{UV}$ in the $255-\mathrm{nm}$ region and hence a continuous monitoring and modelling of $\mathrm{O}_{3}$ is essential to characterise the UV radiation reaching the surface of Mars. Dust not only effects the retrieval of accurate $\mathrm{O}_{3}$ abundances, especially in regions with high $\mathrm{O}_{3}$ (Clancy et al. 2016 ), but can also directly affect $\mathrm{O}_{3}$ abundances due to its radiative impact on photochemistry. In this paper, we have retrieved two Martian years (MY27 and MY28) of total $\mathrm{O}_{3}$ abundances $\left(\mathrm{O}_{3}\right.$ column) from SPICAM to study the seasonal variability of $\mathrm{O}_{3}$ and its correlation with dust and $\mathrm{CO}$. The objectives of this paper comprise (i) a study of the seasonal variation of total $\mathrm{O}_{3}$ in different latitude regions from retrieved and modelled abundances; (ii) a study of the retrieval of Martian $\mathrm{O}_{3}$ in the presence and absence of dust storms and (iii) a study of the correlation of $\mathrm{O}_{3}$ with $\mathrm{CO}$. The model used here is the Laboratoire de Météorologie Dynamique (LMD) photochemistry coupled GCM (LMD-GCM) described later in section 4.

\section{3. $\mathrm{O}_{3}$ retrieval}

The observations from SPICAM UV spectrometer aboard the Mars Express are used to retrieve columnar $\mathrm{O}_{3}$. These observations are available in analogue to digital units (ADU) from the radiance recorded by the spectrometer in the nadir mode (Bertaux et al. 2006; Perrier et al. 2006). The spectral resolution of the spectrometer is about $1 \mathrm{~nm} /$ pixel, and the resolving power is 120 300. SPICAM records the UV radiation in the dayside, backscattered by the atmospheric gases and dust in the Martian atmosphere. Observations are recorded in 110-320 $\mathrm{nm}$ range, allowing the measurement of $\mathrm{O}_{3}$, which has a characteristic Hartley band absorption spectrum in the wavelength range of $210-300 \mathrm{~nm}$, with a peak at $255 \mathrm{~nm}$. This characteristic absorption gets imprinted in the backscattered solar radiation received by SPICAM. In this wavelength region, other species such as $\mathrm{CO}_{2}, \mathrm{~N}_{2}, \mathrm{O}_{2}$ and $\mathrm{H}_{2} \mathrm{O}$ are less absorptive in comparison with $\mathrm{O}_{3}$, which make the $\mathrm{O}_{3}$ column determination easier. For the current retrieval, we have used measurements of $\mathrm{O}_{3}$ absorption cross sections from Malicet et al. (1995), which are consistent with the recent measurements of Gorshelev et al. (2014) and Serdyuchenko et al. (2014). However, Rayleigh scattering and absorption and scattering by dust have to be accounted for while retrieving $\mathrm{O}_{3}$. In order to retrieve $\mathrm{O}_{3}$ values from the SPICAM observations, theoretical spectra need to be derived and fitted. The radiative transfer model and the model atmosphere used to do so are described in section 3.2.

\subsection{Raw data and retrieval method}

The Mars Express which is in an elliptical polar orbit with a 7-h period, started observations in January 2004 at solar longitude $\left(L_{\mathrm{s}}\right)=331^{\circ}$. We have retrieved observations from MY27 and MY28. This corresponds to approximately 4149 orbits from orbit number $61\left(\mathrm{MY} 27, L_{\mathrm{s}}=7^{\circ} ; 19\right.$ March $2004)$ to orbit number $5055\left(\mathrm{MY} 28, L_{\mathrm{s}}=359.74^{\circ}\right.$; 9 December 2007). The numbers of orbits in individual years MY27 and MY28 were 2331 and 1818, respectively. The analysis resulted in around 51,721 high-S/N spectra (MY_27: 28,273 and MY_28: 23,448).

We have taken level 1A observation spectra from the Geosciences Node of ESA's Planetary Science Archive (ftp://psa.esac.esa.int/pub/). The Level 1A data are corrected for dark charge, electronic noise, erroneous data and damages by cosmic rays and saturations. Each nadir observation is typically 30-min long and records almost 1000 spectra, spectral radiance being recorded each second. SPICAM records spectra in five contiguous bins each second. Each bin is characterised by the number of charge-coupled device (CCD) lines grouped together (Bertaux et al. 2006). Spectra recorded in each bin are averaged to obtain a mean spectrum from which $\mathrm{O}_{3}$ is extracted. We then averaged 50 consecutive spectra to improve the signal-to-noise ratio. This results in 30-40 individual spectra. Each recorded spectra (I) is divided by the flux at the top of the atmosphere $(\mathrm{F})$, yielding the radiance factor I/F.

Perrier et al. (2006) have reported that the spectra suffer from the internal stray light by 8 $10 \%$ of its total intensity. Accordingly, we describe here the internal stray light correction that we have applied to each spectrum. Stray light contributions to the data can be taken as $10 \%$ of the 
recorded intensity (Bertaux et al. 2006). Therefore, we integrated each spectrum over the operating range of the SPICAM-UV spectrometer $(\lambda=$ $118-320 \mathrm{~nm})$ :

$$
I=\int I_{\lambda} \mathrm{d} \lambda
$$

Bertaux et al. (2006) provided spectra of stray light for each band. Each of those spectra has been integrated over the wavelength range $118-320 \mathrm{~nm}$. The stray light associated with any particular spectrum recorded by SPICAM at wavelength $\lambda$ is given as

$$
I_{\text {stray }}(\lambda)=0.1 \times I \times\left(I_{b}(\lambda) / \int I_{b}(\lambda) \mathrm{d} \lambda\right),
$$

where $I_{b}(\lambda)$ is the intensity (in ADU) associated with the stray light spectrum. Therefore, the corrected spectra are given as

$$
I_{\text {corrected }}(\lambda)=I_{\text {SPICAM }}(\lambda)-I_{\text {stray }}(\lambda) .
$$

The averaging over 50 consecutive spectra results in 30-40 individual spectra. This has been done in order to increase the signal-to-noise ratio. The final intensity is expressed in terms of kilo Rayleigh $(\mathrm{kR})$ per nanometre, and consequently converted into the radiance factor $(I / F)$, where $\pi F$ is the solar flux received by SPICAM.

\subsection{Forward model}

To simulate a theoretical spectrum corresponding to each observational spectrum, we developed a forward model. We solve the following radiative transfer equation in the nadir direction assuming a plane parallel atmosphere:

$$
\frac{\mathrm{d} I_{\nu}(z)}{\mathrm{d} \tau_{\nu}(z)}=S_{\nu}(z)-I_{\nu}(z)
$$

where $I_{\nu}(z)$ is the spectral radiance at height $z$ in units of power per unit area, per unit solid angle, per unit frequency interval in the neighbourhood of the frequency $\nu . S_{\nu}(z)$ is the source function at height $z$. The optical depth of the atmosphere at height $z$ is defined as

$$
\tau_{\nu}(z)=\int_{0}^{z} k_{\nu}\left(z^{\prime}\right) \rho_{i}\left(z^{\prime}\right) \mathrm{d} z^{\prime},
$$

where $k_{\nu}$ is the coefficient of extinction due to absorption and scattering by a species $i$ whose density is $\rho_{i}$. The integral form of the above radiative transfer equation is written as (Evans 1998)

$$
\begin{aligned}
I_{\nu}(z)= & \int_{0}^{z} S_{\nu}\left(z^{\prime}\right) k_{\nu}\left(z^{\prime}\right) \rho_{i}\left(z^{\prime}\right) \\
& \times \exp \left[-\int_{z^{\prime}}^{z} k_{\nu}(t) \rho_{i}(t) \mathrm{d} t\right] \mathrm{d} z^{\prime} \\
& +I_{\nu}(0) \exp \left(-\tau_{\nu}(z)\right),
\end{aligned}
$$

where the variable $t=z-z^{\prime}$. The first term on the right-hand side represents the scattering contribution of the diffuse radiations and the second term represents the contribution of the direct radiation in the direction of $I_{\nu}(z)$. Numerically, we perform the above integral using the discrete ordinate method and representing the angular part of the source functions $S_{\nu}$ and $I_{\nu}$ in terms of spherical harmonics expansion. The method is called the simple harmonic discrete ordinate method (SHDOM) (Pincus and Evans 2009). This method is computationally more efficient than standard methods. The source function includes contribution due to the scattering and absorption from diffused radiation.

\subsubsection{Model atmosphere for the radiative transfer model}

To retrieve the $\mathrm{O}_{3}$ column from the SPICAM observed radiance, a model atmosphere is required for the geometry of each spectrum. This atmosphere is constructed with data from the Mars Climate Database (MCD) version 5.2 (Millour et al. 2014) and is divided into 12 equal layers up to $60 \mathrm{~km}$. For the retrieval of $\mathrm{O}_{3}$, surface pressure, temperature and dust vertical profile are important inputs and appropriate calculations of dust extinction and Rayleigh scattering are required. The MCD is a result of the three-dimensional (3D) LMD GCM which is a well-tested dynamical model for Mars (Encrenaz et al. 2012; Clancy et al. 2013), hence constructing the model atmosphere from MCD is suitable for our purpose. Among the other inputs, we have provided dust-effective radius and $\mathrm{O}_{3}$ vertical profiles to the radiative transfer model, suitable for the geometry of the corresponding spectra to be fitted.

\subsubsection{Rayleigh scattering}

The Martian atmosphere is composed of $95.7 \%$ $\mathrm{CO}_{2}, 2.07 \%$ Ar and $2.03 \% \mathrm{~N}_{2}$ (Franz et al. 2015), hence being a $\mathrm{CO}_{2}$-dominated atmosphere, it is 2.5 times more scattering than Earth's atmosphere (Forget and Pierrehumbert 1997). Thus, the calculation of $\mathrm{CO}_{2}$ Rayleigh scattering cross section 
becomes important. In earlier studies, theoretical calculation of Rayleigh scattering for $\mathrm{CO}_{2}$ does not agree with measurements (Sneep and Ubachs $2005)$. We have calculated the cross section from the fitted equation $\sigma=\bar{\sigma} \times v^{4+\epsilon}$ with appropriate values of the parameters (Willame et al. 2017). As for the cross sections of $\mathrm{N}_{2}$ and Ar, we have calculated from theory based on the refractive index with data from Thalman et al. (2014). The parameter values are better than $1 \%$ and the experiment was made for the wavelength range between 408 and $532 \mathrm{~nm}$, which we have extrapolated to the UV region that is important for $\mathrm{O}_{3}$ retrieval.

\subsubsection{Dust optical depth and scattering}

Dust scattering and absorption are calculated from the Mie theory considering spherical dust particles. The phase function for dust scattering is calculated from the Legendre series expansion, the coefficients of which are given as inputs to the SHDOM solver. The refractive index in the UV wavelength range of consideration has been taken from Wolff et al. (2010). In figure 1, the phase function calculated from the Mie theory for a particle of radius $0.1 \mu \mathrm{m}$ and its comparison with the Henyey-Greenstein phase function is shown. In our calculation, we have used the full series of the phase function, a truncation being used only when the values of the coefficients are less than 0.00001 . The scattering and extinction efficiencies $\left(S_{\text {ext }}\right.$ and $\left.Q_{\text {ext }}\right)$ are shown in figure 2 for wavelength $220 \mathrm{~nm}$. These are calculated for the refractive index, $m=1.486-\mathrm{i}^{*} 0.0155$. The real part is a slowly varying function of wavelength and this is

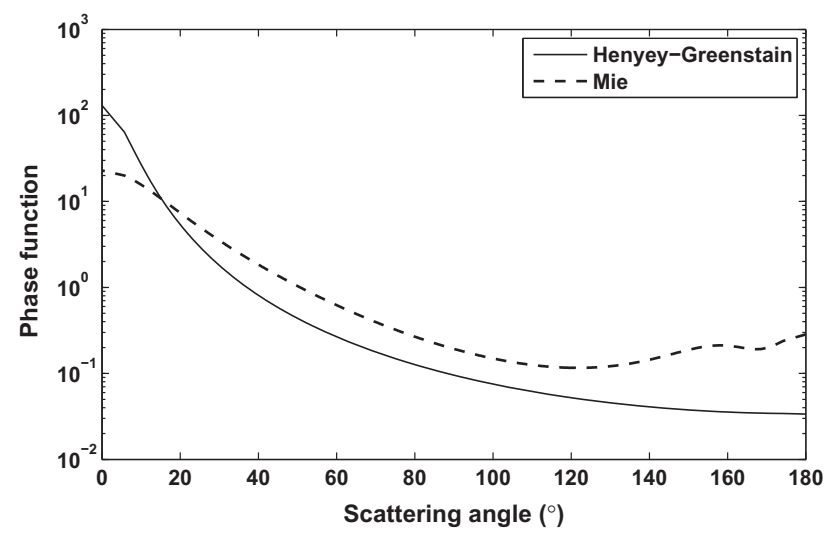

Figure 1. Phase function for particles of radius $0.1 \mu \mathrm{m}$ calculated from Mie theory and compared with the HenyeyGreenstein phase function.

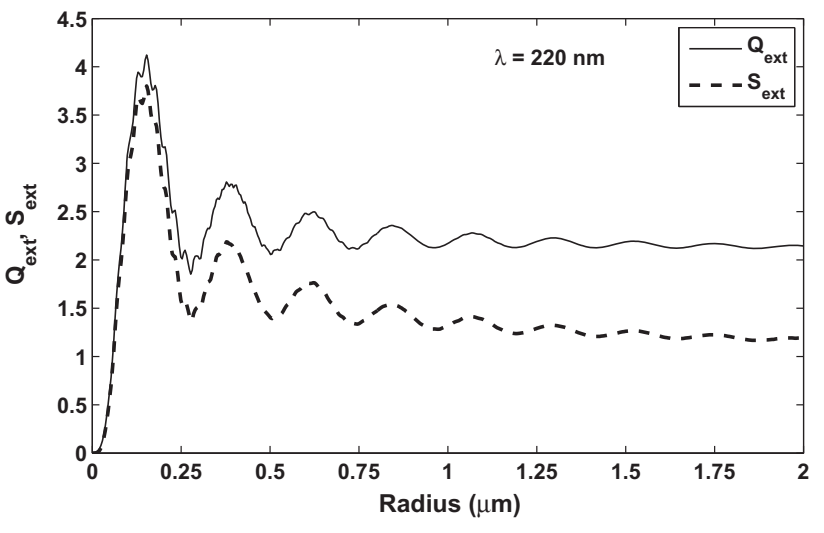

Figure 2. Scattering and extinction efficiencies $\left(S_{\text {ext }}\right.$ and $\left.Q_{\text {ext }}\right)$ for $m=1.486-\mathrm{i}^{*} 0.0155$ and $\lambda=220 \mathrm{~nm}$.

why we have taken a constant value 1.486 for the present retrieval (Wolff et al. 2009). As for the imaginary part, the proper behaviour with wavelength in the region 200-300 $\mathrm{nm}$ is not known; hence, we have used a value suggested by Wolff et al. (2009) for $\lambda=668 \mathrm{~nm}$. The real part represents the dust scattering while the imaginary part represents absorption by dust. As can be seen from figure 2, the single scattering albedo defined as the ratio $S_{\text {ext }} / Q_{\text {ext }}$ is $>0.9$ for smaller particles. For particles with a higher radius, the single scattering albedo is reduced to values approaching 0.6.

\subsection{Fitting method}

Now that we have both theoretical and observational spectra, we compare them by using a best fit to determine columnar $\mathrm{O}_{3}$. For this, we select nine points from the observation spectra in the range $210-300 \mathrm{~nm}$. Corresponding to the observed radiance at each point, a theoretical radiance has been calculated using the radiative transfer model discussed in section 3.2, with a prior value of $\mathrm{O}_{3}$ column, surface albedo and dust opacity. Mars surface albedo varies from place to place and therefore albedo at 210 and $300 \mathrm{~nm}$ are also retrieved simultaneously with $\mathrm{O}_{3}$. However, the values of albedo are forced to be $<1$. All parameters are kept positive throughout the retrieval. In order to determine total column $\mathrm{O}_{3}$, the sum of the square of weighted differences $\left(\chi^{2}\right)$ has to be minimised. For this purpose, we have used the Levenberg-Marquardt minimisation method (LM method) which is a nonlinear chi-square minimisation method where multiple parameters can be fitted. The LM method which updates the parameter values adaptively, works better than the gradient 
descent and Gauss-Newton methods. The convergence criterion for the method is that $\chi^{2}$ defined as follows, is $<1$ :

$$
\chi^{2}=(y-\widehat{y}(p))^{\mathrm{T}} W(y-\widehat{y}(p))
$$

where $y\left(\lambda_{\mathrm{i}}\right)$ are the observations which are functions of wavelength $\lambda_{\mathrm{i}}$ and $\hat{y}\left(\lambda_{\mathrm{i}} ; p\right)$ is the fitting function for a vector of parameter $p$ and $W$ is the inverse of the error covariance matrix. We estimate the uncertainties on the $\mathrm{O}_{3}$ column due to our retrieval method. For a known $\mathrm{O}_{3}$ column, we generate synthetic spectra with the forward model. $\mathrm{O}_{3}$ columns are then retrieved assuming that these synthetic spectra were observed by SPICAM. For high dust and moderate $\mathrm{O}_{3}(\sim 10 \mu \mathrm{m}$ atm $)$, the errors range between $10 \%$ and $30 \%$. The errors are in the same range for low dust and low $\mathrm{O}_{3}(\sim 0.5 \mu \mathrm{m}$ atm). For low dust and high $\mathrm{O}_{3}(\sim 20 \mu \mathrm{m}$ atm $)$, errors in the retrieved $\mathrm{O}_{3}$ values are within 10\% (Perrier et al. 2006). An example of a fitted spectrum for the orbit number 902 (latitude $=31.92^{\circ} \mathrm{N}$ and $L_{\mathrm{s}}=95.31^{\circ}$ ) is shown in figure 3 , where the radiance factor (as defined in section 3.1) is plotted against the wavelength. An $\mathrm{O}_{3}$ columnar value of $0.23 \mu \mathrm{m}$ atm is retrieved for this spectrum. The retrieved values of albedo are commensurate with a poor reflector of the UV radiation, and are lower compared to those retrieved by Perrier et al. (2006) in the polar region and also during some seasons in the equatorial region. We have observed that the retrieved $\mathrm{O}_{3}$ values are not very sensitive to the values of albedo especially when there are clouds present.

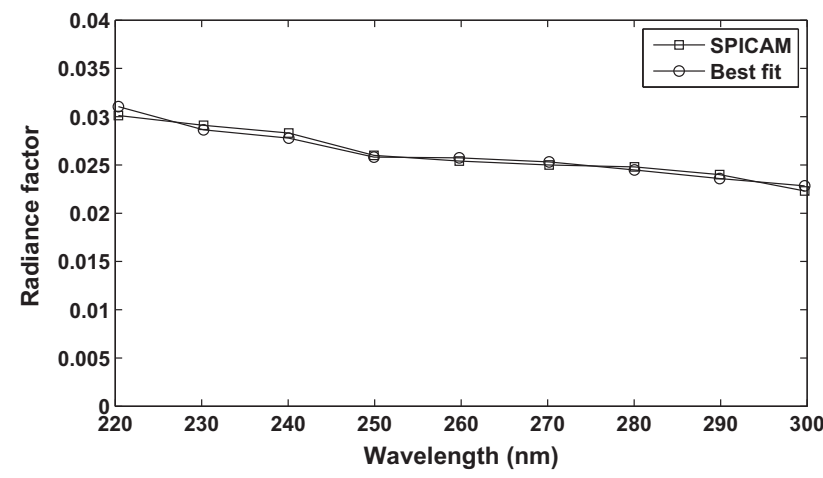

Figure 3. Fitted spectrum for orbit number 902 (latitude $=$ $\left.31.92^{\circ} \mathrm{N}, L_{\mathrm{s}}=95.31^{\circ}\right)$. An $\mathrm{O}_{3}$ columnar value of $0.23 \mu \mathrm{m}$ atm is retrieved for this spectrum.

\section{General circulation model}

In this work, we use the LMD-GCM, developed in collaboration with the Laboratoire de Météorologie Dynamique, the Open University, the University of Oxford and the Instituto de Astrofisica de Andalucia. This model uses physical parameterisations such as effects due to $\mathrm{CO}_{2}$ and dust adsorption and emission, thermal conduction in the soil, $\mathrm{CO}_{2}$ condensation and sublimation, sub-grid scale dynamics, vertical diffusion and convection (Forget et al. 1999). These are coupled to a spectral dynamical core and van-Leer advection scheme with mass conservation to transport tracers.

The dust distribution is prescribed horizontally using an interpolation of numerous sets of observations from orbiters and landers using the Kriging method (Montabone et al. 2015) and vertically distributed treating it at equal footing same as the tracers (Forget et al. 1999). We run the model on a grid of $3.75^{\circ}$ latitude $\times 5.675^{\circ}$ longitude, with 32 vertical hybrid sigma levels extending to an altitude of $\sim 122 \mathrm{~km}$.

$\mathrm{O}_{3}$, water vapour, $\mathrm{CO}$ and other species are simulated by a photochemical module (Lefèvre et al. 2004) coupled with the GCM. The module consists of 36 chemical and 14 photochemical reactions. Chemical species are updated every $10 \mathrm{~min}$ of cycling over each atmospheric column, computing the tendencies for each chemical species at each level in the column. The chemical species are then transported by the van-Leer advection scheme. The advection scheme uses wind fields updated by the dynamical core to determine the $\mathrm{O}_{3}$ concentration at each model grid point every $30 \mathrm{~min}$. The chemical fields are exchanged between the GCM and photochemical model each time step for a fully interactive coupling between dynamics, physical parameterisations and chemical species. The model runs with appropriate boundary conditions. We run the model on the PRL 100 Tf high-performance computing (HPC) Linux cluster with 100 nodes at the Physical Research Laboratory Ahmedabad, India.

\section{Results and discussions}

Longitudinally averaged columnar values of $\mathrm{O}_{3}$ retrieved from SPICAM for MY27 are shown as a function of latitude and season $\left(L_{\mathrm{s}}\right)$ in figure 4 . For the current retrieval, the highest $\mathrm{O}_{3}$ columnar values are within $25 \mu \mathrm{m}$ atm over the northern polar 

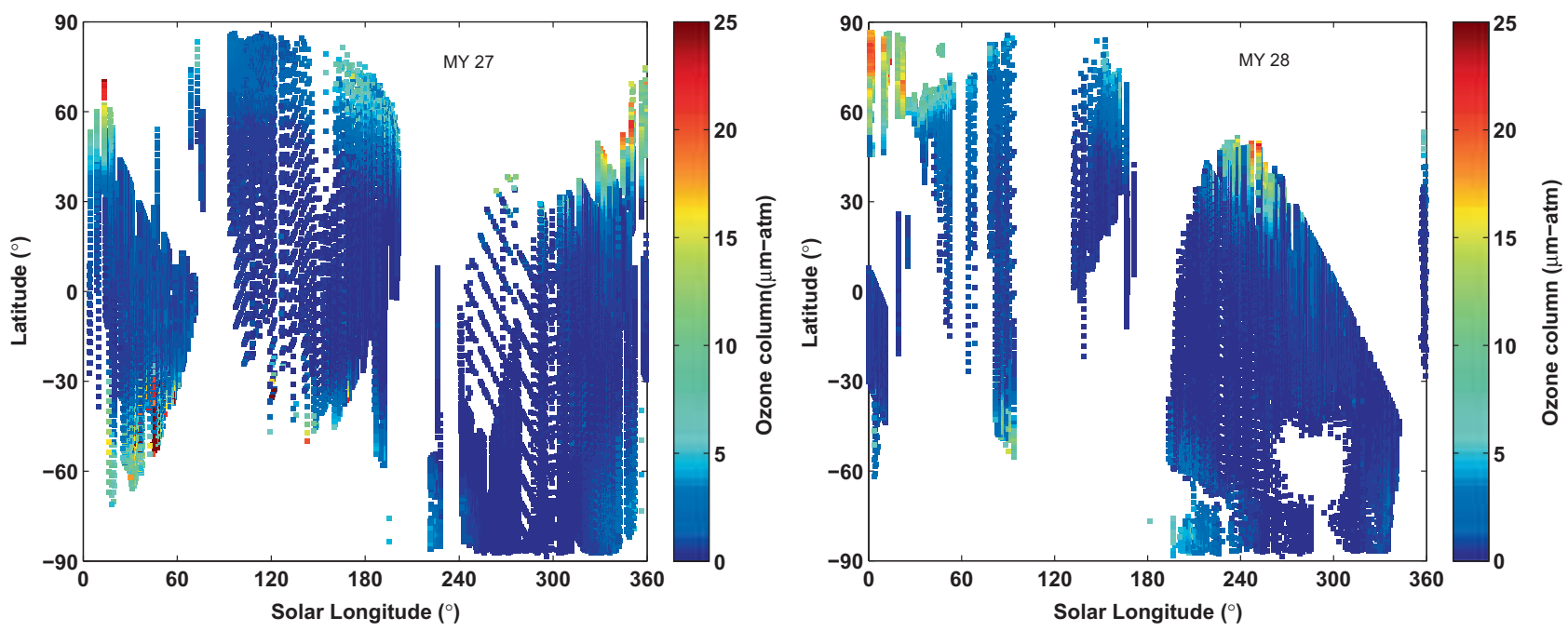

Figure 4. $\mathrm{O}_{3}$ columnar values retrieved from SPICAM for MY27 as a function of latitude and season.

region during spring and winter. The $\mathrm{O}_{3}$ retrieved for this work matches well with those retrieved by Willame et al. (2017) and Clancy et al. (2016), who have reported similar maximum values. However, Perrier et al. (2006) reported high columnar $\mathrm{O}_{3}$ amounts of about $40 \mu \mathrm{m}$ atm. The seasonal and regional features of the $\mathrm{O}_{3}$ column can be seen in figure 4. In the Martian atmosphere, $\mathrm{O}_{3}$ is anticorrelated with the water vapour (Krasnopolsky 1993; Nair et al. 1994; Lefèvre et al. 2004), since $\mathrm{O}_{3}$ is destroyed by the odd $\mathrm{H}$ radicals produced from water vapour. This results in higher column values for $\mathrm{O}_{3}$ during winter and almost negligible values during summer. During winter, water vapour condenses on the poles leading to a lesser loss of $\mathrm{O}_{3}$ and thus higher column amounts. Over the high northern latitudes in spring, high $\mathrm{O}_{3}$ values in the range $12-21 \mu \mathrm{m}$ atm are retrieved. During the polar winter, night observations are not possible. During summer, around $L_{\mathrm{s}}=120^{\circ}, \mathrm{O}_{3}$ values are of the order of $1 \mu \mathrm{m}$ atm while they increase at the end of summer to $5 \mu \mathrm{m}$ atm. During the southern summer, the columnar values of $\mathrm{O}_{3}$ are $<0.1 \mu \mathrm{m}$ atm, which is a direct effect of hygropause elevation.

The $\mathrm{O}_{3}$ data retrieved and discussed above are averaged over latitude intervals of $30^{\circ}$ and $L_{\mathrm{s}}$ intervals of $2^{\circ}$ and their comparison with simulations from the LMD-GCM is shown in figure 5 for MY27 and MY28 and for the six latitude regions: tropical $\left(0^{\circ}\right.$ to $\left.\pm 30^{\circ}\right)$, mid $\left( \pm 30^{\circ}\right.$ to $\left.\pm 60^{\circ}\right)$ and high $\left( \pm 60^{\circ}\right.$ to $\pm 90^{\circ}$ ) latitudes. Certain features are clearly visible in the GCM-simulated $\mathrm{O}_{3}$ variability. Firstly, maximum $\mathrm{O}_{3}$ columns $(\sim 20 \mu \mathrm{m}$ atm $)$ are seen at high latitudes and the polar region in the southern fall/winter due to low water vapour. This model simulated peak occurs at $L_{\mathrm{s}}=100^{\circ}$ for polar latitudes and between $L_{\mathrm{s}}=50^{\circ}$ and $100^{\circ}$ for high latitudes $\left(30^{\circ} \mathrm{S}\right.$ and $\left.60^{\circ} \mathrm{S}\right)$. The $\mathrm{O}_{3}$ columns retrieved from SPICAM observations also show high latitude $\mathrm{O}_{3}$ maxima but for polar winter, data were not available. In contrast, very low $\mathrm{O}_{3}$ due to the release of water vapour from the polar cap can be seen from $L_{\mathrm{s}}=240-360^{\circ}$ (southern summer) in the southern polar region. $\mathrm{O}_{3}$ retrievals for the southern polar region for $L_{\mathrm{s}}=30-190^{\circ}$ are not available, as SPICAM cannot observe the winter poles due to the absence of solar irradiance. But from the comparison with GCM results, a reasonable match is seen with the retrieved $\mathrm{O}_{3}$ data in different regions. In the equatorial regions, the seasonal variation of $\mathrm{O}_{3}$ is not as pronounced as in the polar region.

The global map of dust optical depth retrieved from SPICAM is shown in figure 6 as a function of season for MY28. The figure indicates a background aerosol loading with optical depths $<0.5$ between $L_{\mathrm{s}}=0^{\circ}$ and $160^{\circ}$. Optical depths measured by a thermal emission imaging system (THEMIS) at $9.3 \mu \mathrm{m}$ start to increase after $L_{\mathrm{s}}=220^{\circ}$ during MY28, reaching about 1.2 at $L_{\mathrm{s}}=280^{\circ}$ during the global dust storm period of that year (Sheel and Haider 2016). Similarly, the global dust storm can be seen from the current retrieval of dust optical depth (figure 6), when optical depths start increasing only after $L_{\mathrm{s}}=220^{\circ}$ and during $L_{\mathrm{s}}=240-330^{\circ}$, the values increase to $>1.0$. The retrieval is thus able to capture the global dust storm and thus compare qualitatively with the THEMIS observations (Smith 2009). After the major storm, it took about a few months for the 


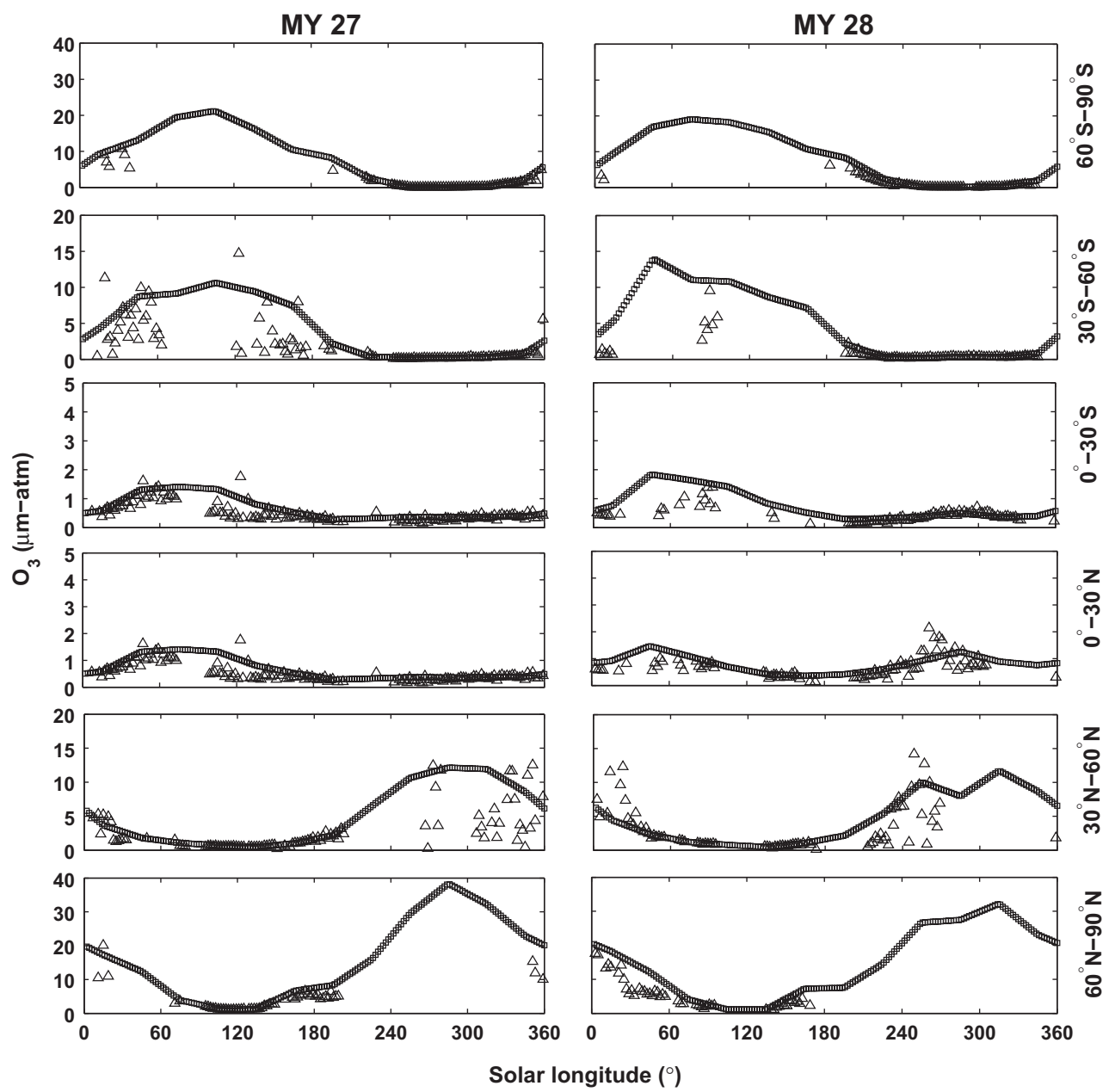

Figure 5. Zonally averaged $\mathrm{O}_{3}$ retrieved from SPICAM and its comparison with simulations from the LMD-GCM for MY27 and MY28, averaged over the six latitude regions: tropical (0 to \pm 30$)$, mid ( \pm 30 to \pm 60$)$ and high ( \pm 60 to \pm 90$)$.
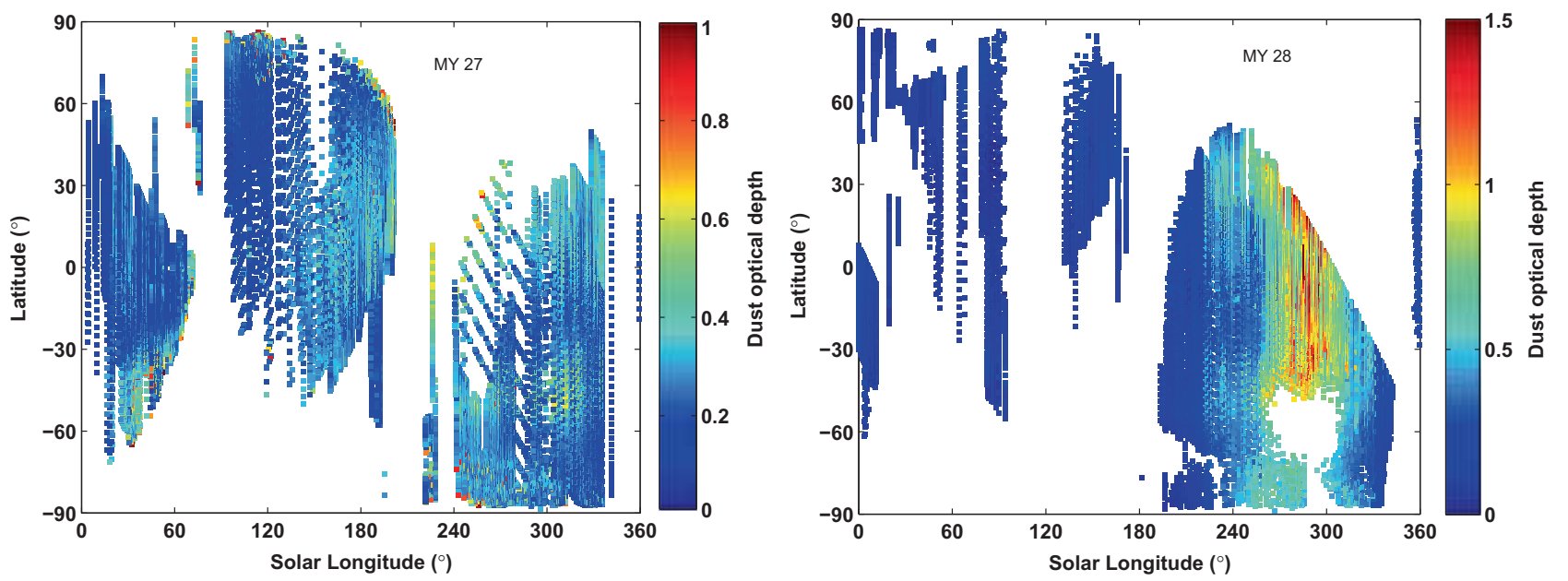

Figure 6. Dust optical depth retrieved from SPICAM at $\lambda=300 \mathrm{~nm}$ for MY28 as a function of latitude and season.

dust to settle down to the background dust loading. Many of these major dust storms begin in the subtropical region in the southern summer season after perihelion, when Mars receives a higher amount of radiative energy from the Sun compared to other seasons. The increased solar insolation increases the temperature and wind speeds lift dust from the surface into the 

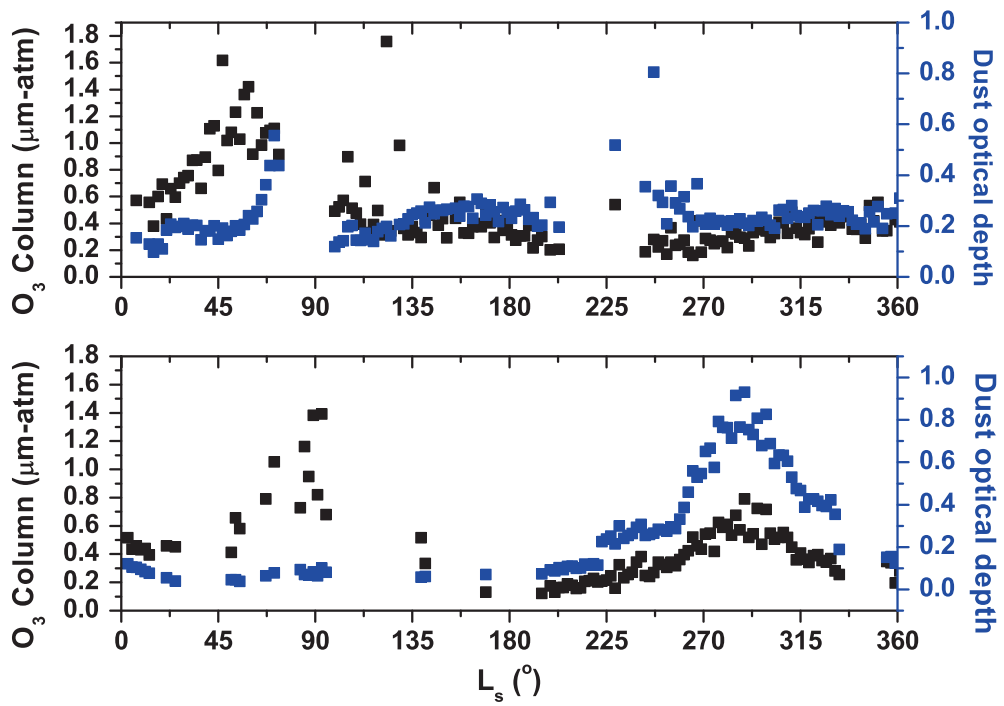

Figure 7. Correlation of $\mathrm{O}_{3}$ and dust retrieved from observations by SPICAM, for the latitude region $0-30^{\circ} \mathrm{S}$. The upper panel is for MY27 (no global dust storm) and the lower panel is for MY28 (global dust storm).

atmosphere of Mars (Lemmon et al. 2015). The retrieval of dust optical depths can be affected by the presence of clouds, as the retrieval methods yield artificially high dust optical depths, possibly due to the presence of water-ice clouds (which we do not retrieve). In general, clouds occur in the cold aphelion seasons. For example, dust optical depths are found higher in the southern polar region during $L_{\mathrm{s}}=0-50^{\circ}$ in MY27. Due to a lack of data in the southern polar region, those high values of dust optical depth affected by clouds could not be seen during MY28.

\section{$5.1 \mathrm{O}_{3}$ and dust}

$\mathrm{O}_{3}$ is very reactive, and apart from being sensitive to changes in water vapour in the atmosphere, it is also affected by the dust loading. Dust, which is known to affect various other parameters in the atmosphere, including the ionosphere (Sheel and Haider 2016), is highly variable. Many dust storms originate in the southern hemisphere and some of these grow into global dust storms in certain years, while regional or local dust storms occur almost every year (Sheel and Haider 2016). A climatology of 9 Martian years of dust loading has revealed that there is always a background aerosol loading of optical depth of about 0.1 between $L_{\mathrm{S}}=0^{\circ}$ and $160^{\circ}$, corresponding to a period when dust storms are absent, while the optical depth increases every year (e.g., by a factor of 5 at the southern summer tropics), to values in the range $0.3-0.5$ corresponding to regional dust storms which typically occur at $L_{\mathrm{s}}=220^{\circ}$ (Sheel and Haider 2016). For global dust storms, the peak optical depth can reach up to, e.g., 1.7 in the southern tropics during the MY25 global dust storm at $L_{\mathrm{s}}=210^{\circ}$. During the regional and global dust storms, detached dust layers have also been observed and modelled (cf. Sheel and Haider 2016), which could lift dust to altitudes up to $50 \mathrm{~km}$, between $L_{\mathrm{s}}=150^{\circ}$ and $280^{\circ}$. Here, we consider two cases: (i) MY28 which witnessed a global dust storm and (ii) the preceding year MY27, in which a regional storm did occur, though it could not eventually turn into a global storm. In figure 7, we have shown the seasonal behaviour of $\mathrm{O}_{3}$ and dust (total optical depth) for MY27 and MY28 for southern low latitudes $\left(0-30^{\circ} \mathrm{S}\right)$.

A comparison of the panels of figure 7 indicates an increase of $\mathrm{O}_{3}$ with the increase of dust. As discussed above (figures 4 and 5 ), not much variation in $\mathrm{O}_{3}$ is seen in the tropical latitudes. However, in figure 7 , we see a striking feature of $\mathrm{O}_{3}$ increasing with dust during the global dust storm year of MY28 from $L_{\mathrm{s}}=210^{\circ}$ to $L_{\mathrm{s}}=330^{\circ}$. The $\mathrm{O}_{3}$ columnar values continue to increase after $L_{\mathrm{s}}=225^{\circ}$ in MY28 (figure 7), for dust optical depths more than 0.5 . The water vapour column shown in figure 8 indicates that for the 2 years, the amount of water vapour available in the atmosphere is constant (Navarro et al. 2014); therefore, the increase in $\mathrm{O}_{3}$ can be attributed to the increased dust loading and its radiative impact. This behaviour of the $\mathrm{O}_{3}$ column during the global dust storm can be validated with the LMD-GCM simulation for MY28 with high dust (see figure 9). Other model simulations show that the photodissociation rates 
are drastically reduced during dust storms due to the radiative impact of dust, thereby increasing $\mathrm{O}_{3}$ abundances which may be typically increased by 10-50\% (Lindner 1988).

\section{$5.2 \mathrm{CO}-\mathrm{O}_{3}$ correlation}

$\mathrm{CO}$ in the Martian atmosphere has been observed in the 1.6 and $2.35 \mu \mathrm{m}$ region by ground-based and spacecraft spectroscopy by OMEGA and PFS on the Mars Express, CRISM on Mars Reconnaissance Orbiter, and the heterodyne instrument for the far infrared (HIFI) aboard the Herschel space observatory (cf. Hartogh et al. 2010). CO and $\mathrm{O}_{3}$ are closely related via their common source (photolysis of $\mathrm{CO}_{2}$ ) and their common sink (loss with $\mathrm{HO}_{x}$ radicals). The chemical lifetime of $\mathrm{CO}$ in the Martian atmosphere is in order of years while the $\mathrm{O}_{3}$ lifetime is of few minutes, therefore the

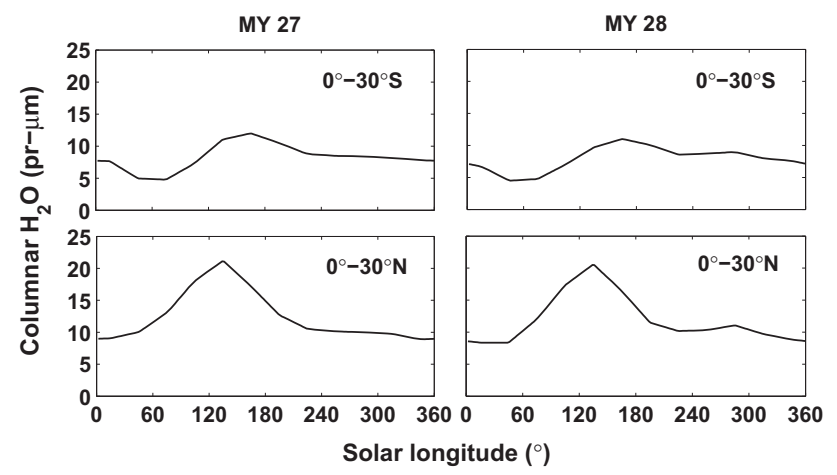

Figure 8. Seasonal variation of zonally averaged water vapour columnar abundance simulated by the LMD-GCM for MY27 and MY28 and for the latitude regions $30-0^{\circ} \mathrm{S}$ and $0-30^{\circ} \mathrm{N}$.
$\mathrm{CO}-\mathrm{O}_{3}$ correlation cannot be expected based on their chemistry. However, it has been shown that the dynamical transport of $\mathrm{O}$ atoms from sunlit latitudes increases $\mathrm{O}_{3}$ over the southern polar region (Lefèvre et al. 2008). CO being a non-condensable and stable gas is also used as a dynamical tracer. Therefore, in order to investigate the dynamical effect on the $\mathrm{O}_{3}$ columnar amount, we evaluate the correlation of GCM simulated $\mathrm{O}_{3}$ column (as SPICAM observations for polar nights are not available) with the GCM-simulated CO column for each season and over six latitude regions as shown in figure 10. Modelled CO concentrations qualitatively compare well with observations (Smith et al. 2009). As can be seen from the figure, CO does not show much variation with $\mathrm{O}_{3}$ over the latitude region $60^{\circ} \mathrm{S}-60^{\circ} \mathrm{N}$ compared to over the polar region, indicating insignificant dynamical contributions to the $\mathrm{O}_{3}$ column. However, during winter over the polar region, the $\mathrm{CO}$ column increases with the $\mathrm{O}_{3}$ column, the correlation being greater over the southern polar region compared to the northern region. This indicates a higher dynamical contribution towards the increase in the $\mathrm{O}_{3}$ columnar value over the southern polar winter.

To derive the percentage contribution of the dynamics, we compare the $\mathrm{O}_{3}$ vertical profile from the 3D and the one-dimensional (1D) version of the LMD-GCM, as the 3D version includes the large-scale Martian dynamics. Apart from this, all other physical processes such as $\mathrm{CO}_{2}$ condensation, radiative interaction within the atmosphere, water cycle, dust condition and solar insolation are kept the same. Both the models were initiated at $L_{\mathrm{s}}=0$ and ran with the full photochemistry module of
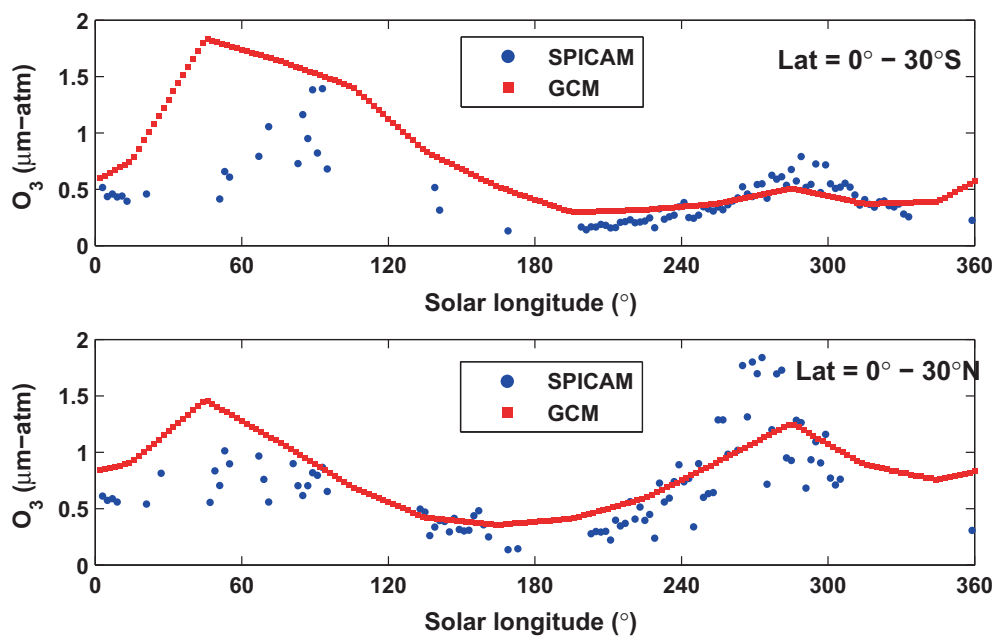

Figure 9. Comparison of the retrieved $\mathrm{O}_{3}$ column from SPICAM observation with the GCM simulated values for MY28 and the latitude regions $30-0^{\circ} \mathrm{S}$ and $0-30^{\circ} \mathrm{N}$. 

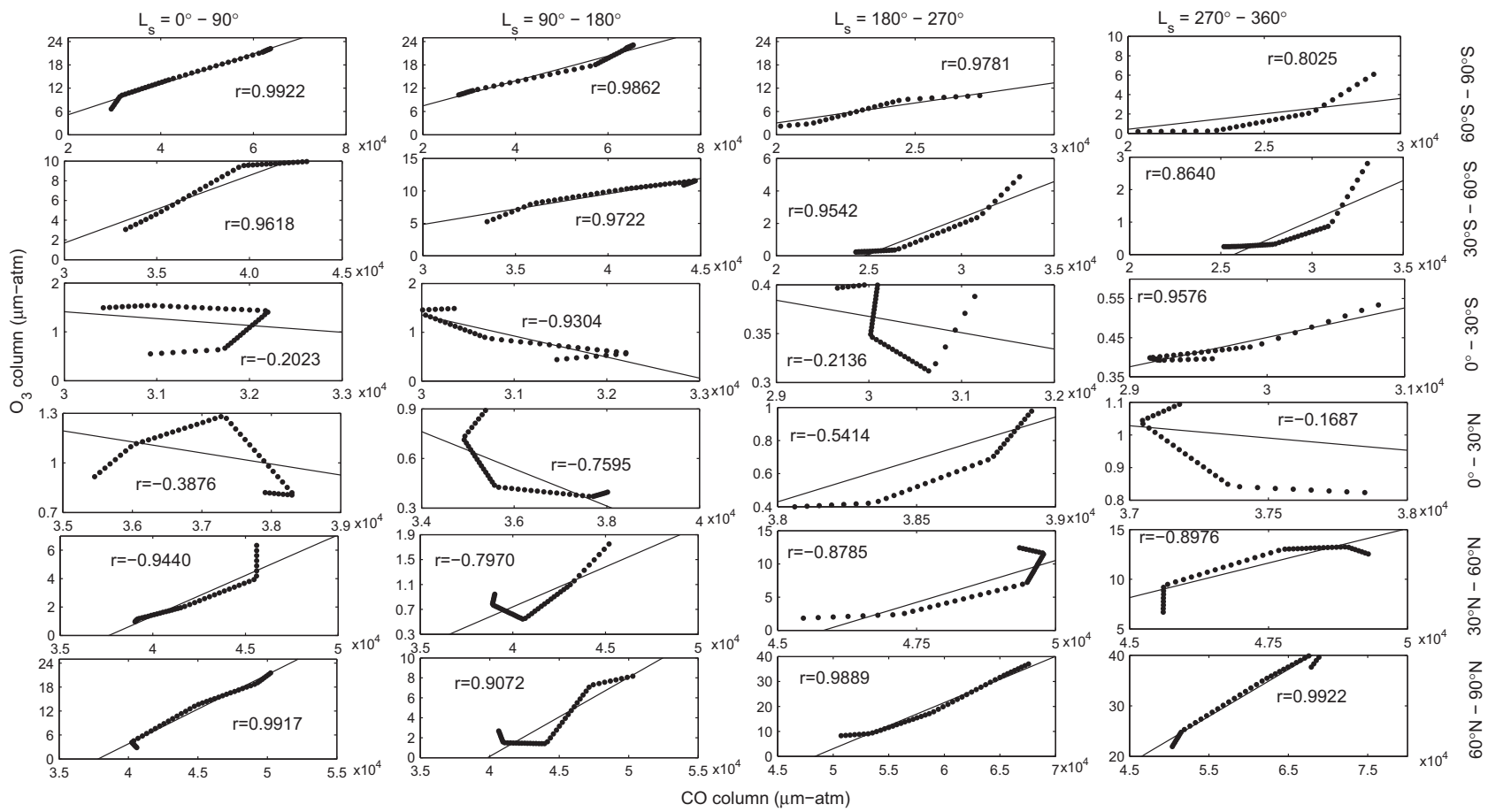

Figure 10. Correlation between $\mathrm{O}_{3}$ and $\mathrm{CO}$ from the LMD-GCM, for the four seasons: spring, summer, autumn and winter, and the six latitude regions as in figure 5 .

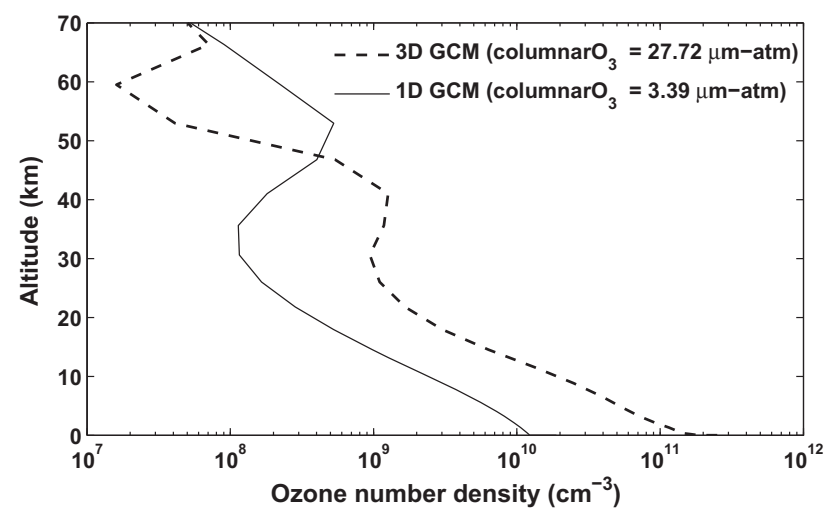

Figure 11. $\mathrm{O}_{3}$ vertical profiles simulated for the $3 \mathrm{D}$ and $1 \mathrm{D}$ version of LMD-GCM. The 3D version includes dynamics whereas the $1 \mathrm{D}$ version does not include dynamics.

Lefèvre et al. (2004). For the 1D model, we input a reference surface pressure of $610 \mathrm{~Pa}$ and a temperature profile for the polar region. In figure 11, we show the number density of $\mathrm{O}_{3}$ derived from both model calculations over $70^{\circ} \mathrm{S}$ during $L_{\mathrm{s}}=45^{\circ}$. In polar nights, the concentration of $\mathrm{O}$ atoms reduces drastically due to the absence of its major source (photolysis of $\mathrm{CO}_{2}$ and $\mathrm{O}_{2}$ ) as well as the absence of transport. This leads to a decrease in $\mathrm{O}_{3}$ concentrations too, reflecting a decrease in the $\mathrm{O}_{3}$ column of about $\sim 24 \mu \mathrm{m}$ atm compared to the case when dynamics is present (figure 11). The shape of the $\mathrm{O}_{3}$ vertical profile is decided by the $\mathrm{H}_{2} \mathrm{O}$ profile and the hygropause altitude. In the case of $3 \mathrm{D}$ simulation, hygropause occurs at a lower altitude, and hence, the second peak in $\mathrm{O}_{3}$ occurs at a lower altitude compared to the $1 \mathrm{D}$ simulation. The exact cause of the increase in water vapour saturation level in $1 \mathrm{D}$ simulation could not be pointed out.

\section{Summary and conclusions}

We have retrieved $\mathrm{O}_{3}$ columnar abundances and dust for MY27-MY28 from raw spectral radiances recorded by SPICAM aboard Mars Express and by using a forward radiative transfer model. We have also run the photochemistry coupled LMDGCM on our HPC cluster, to simulate $\mathrm{O}_{3}, \mathrm{CO}$ and water vapour.

The seasonal variability of total columnar $\mathrm{O}_{3}$ was studied for 2 Martian years at tropical, mid and high latitudes. Seasonal variations in $\mathrm{O}_{3}$ are not prominent in tropical latitudes, with $\mathrm{O}_{3}$ column values observed in this region below 10 $\mu \mathrm{m}$ atm. For mid-latitudes, $\mathrm{O}_{3}$ exhibits a peak in both northern and southern winters. The GCM simulations compare reasonably well with observations in these regions. A pronounced seasonal variability of $\mathrm{O}_{3}$ is seen in the GCM results in high latitudes of both hemispheres, with a maximum in winter and minimum in summer. 
Unfortunately, SPICAM observations are not available very frequently in the polar region. An $\mathrm{O}_{3}$-water vapour anti-correlation is seen at high latitudes, as reported by earlier studies.

We have also retrieved dust optical depths from SPICAM along with $\mathrm{O}_{3}$, and find that during dust storms, $\mathrm{O}_{3}$ columnar amounts increase with the increase in dust optical depth due to the radiative impact of dust. The increase of $\mathrm{O}_{3}$ can be as high as $50 \%$ of the $\mathrm{O}_{3}$ without global dust storm. A similar result can be seen in $\mathrm{O}_{3}$ simulated by the LMD-GCM for the dark dust storm of MY28.

To study the effect of dynamics on $\mathrm{O}_{3}$ columnar abundance, the correlation between GCMsimulated $\mathrm{CO}$ and $\mathrm{O}_{3}$ has been analysed. We find that the southern polar region exhibits a higher increase in the $\mathrm{O}_{3}$ column due to the transport of oxygen atoms. During $L_{\mathrm{s}}=45^{\circ}$, the $\mathrm{O}_{3}$ column over the southern polar region can increase from 3 to $27 \mu \mathrm{m}$ atm due to dynamical effect. On the other hand, in the northern polar region, the dynamical contribution is much less than the chemical contribution, while over the equator and tropical region, the dynamical effect is insignificant.

We have studied the seasonal variation of $\mathrm{O}_{3}$ retrieved from SPICAM observations and simulated by the LMD-GCM, for different latitude regions. The seasonal variability is more prominent for higher latitudes compared to lower latitudes. The gross features are similar to that reported by previous studies. The retrieved $\mathrm{O}_{3}$ values during dust storms are high, which we attribute to the radiative impact of dust. We also identify the effect of dynamics on the columnar $\mathrm{O}_{3}$, made possible by the 3D GCM simulations.

\section{Acknowledgements}

The authors would like to thank Francios Forget and Ehouran Millour for their extensive support in providing the source code of their LMD-GCM, which was then run on the $100 \mathrm{Tf}$ high-performance computing system at our institute (PRL).

\section{References}

Barth C A and Hord C W 1971 Mariner ultraviolet spectrometer: Topography and polar cap; Science 173(3993) 197-201.

Barth C A, Hord C W, Stewart A I, Lane A L, Dick M L and Anderson G P 1973 Mariner 9 ultraviolet spectrometer experiment: Seasonal variation of ozone on Mars; Science $\mathbf{1 7 9}(\mathbf{4 0 7 5})$ 795-796.
Bertaux J L, Korablev O, Perrier S, Quemerais E, Montmessin F, Leblanc F and Fedorova A 2006 SPICAM on Mars express: Observing modes and overview of UV spectrometer data and scientific results; J. Geophys. Res. Planets 111(E10), https://doi.org/10.1029/ 2006JE002690.

Blamont J and Chassefiere E 1993 First detection of ozone in the middle atmosphere of Mars from solar occultation measurements; Icarus 104(2) 324-336.

Clancy R T, Wolff M J, James P B, Smith E, Billawala Y N, Lee S W and Callan M 1996 Mars ozone measurements near the 1995 aphelion: Hubble space telescope ultraviolet spectroscopy with the faint object spectrograph; $J$. Geophys. Res. Planets 101(E5) 12,777-12,783.

Clancy R T, Sandor B J, García-Muñoz A, Lefèvre F, Smith M D, Wolff M J, Montmessin F, Murchie S L and Nair H 2013 First detection of Mars atmospheric hydroxyl: CRISM Near-IR measurement versus LMD GCM simulation of $\mathrm{OH}$ Meinel band emission in the Mars polar winter atmosphere; Icarus 226 272-281, https://doi.org/ 10.1016/j.icarus.2013.05.035.

Clancy RT, Wolff M J, Lefèvre F, Cantor B A, Malin M C and Smith M D 2016 Daily global mapping of Mars ozone column abundances with MARCI UV band imaging; Icarus 266 112-133.

Encrenaz T, Greathouse T K, Lefèvre F and Atreya S K 2012 Hydrogen peroxide on Mars: Observations, interpretation and future plans; Planet. Space Sci. 68 3-17.

Evans K F 1998 The spherical harmonics discrete ordinate method for three-dimensional atmospheric radiative transfer; J. Atmos. Sci. 55 429-446.

Fast K, Kostiuk T, Espenak F, Annen J, Buhl D, Hewagama T and Schmülling F 2006 Ozone abundance on Mars from infrared heterodyne spectra: I. Acquisition, retrieval, and anti-correlation with water vapor; Icarus $\mathbf{1 8 1}(\mathbf{2})$ 419-431.

Fast K E, Kostiuk T, Lefèvre F, Hewagama T, Livengood T A, Delgado J D, Annen J and Sonnabend G 2009 Comparison of HIPWAC and Mars express SPICAM observations of ozone on Mars 2006-2008 and variation from 1993 IRHS observations; Icarus 203(1) 20-27.

Fedorova A, Korablev O, Bertaux J-L, Rodin A, Kiselev A and Perrier S 2006 Mars water vapor abundance from SPICAM IR spectrometer: Seasonal and geographic distributions; J. Geophys. Res. 111 E09S08, https://doi.org/ 10.1029/2006JE002695.

Forget F and Pierrehumbert R T 1997 Warming early Mars with carbon dioxide clouds that scatter infrared radiation; Science 278 1273-1276.

Forget F, Hourdin F, Fournier R, Hourdin C, Talagrand O, Collins M, Lewis S R, Read P L and Huot J-P 1999 Improved general circulation models of the Martian atmosphere from the surface to above $80 \mathrm{~km} ; J$. Geophys. Res. 104 24155-24175, https://doi.org/10.1029/ 1999JE001025.

Franz H B, Trainer M G, Wong M H, Maha_y P R, Atreya S K, Manning H L and Stern J C 2015 Reevaluated Martian atmospheric mixing ratios from the mass spectrometer on the Curiosity rover; Planet. Space Sci. 109 154-158.

Gierasch P J and Goody R M 1972 The effect of dust on the temperature of the Martian atmosphere; J. Atmos. Sci. 29 400-401. 
González-Galindo F, López-Valverde M A, Angelats i Coll $\mathrm{M}$ and Forget F 2005 Extension of a Martian general circulation model to thermospheric altitudes: UV heating and photochemical models; J. Geophys. Res. 110 E09008, https://doi.org/10.1029/2004JE002312.

Gorshelev V, Serdyuchenko A, Weber M, Chehade W and Burrows J P 2014 High spectral resolution ozone absorption cross-sections - Part 1: Measurements, data analysis and comparison with previous measurements around 293 K; Atmos. Meas. Tech. 7 609-624.

Guzewich S D, Talaat E R, Toigo A D, Waugh D W and McConnochie T H 2013 High-altitude dust layers on Mars: Observations with the Thermal Emission Spectrometer; $J$. Geophys. Res. Planets. 118 1177-1194, https://doi.org/ 10.1002 /jgre.20076.

Hartogh P, Błecka M I, Jarchow C, Sagawa H, Lellouch E, de Val-Borro M and Cavalié T 2010 First results on Martian carbon monoxide from Herschel/HIFI observations; Astron. Astrophys. 521 L48, https://doi.org/10. 1051/0004-6361/201015159.

Heavens N G, Richardson M I, Kleinböl A, Kass D M, McCleese D J, Abdou W, Benson J L, Schofield J T, Shirley J H and Wolkenberg P M 2011 The vertical distribution of dust in the Martian atmosphere during northern spring and summer: 2. The high altitude tropical dust maximum; J. Geophys. Res. 116 E01007, https://doi.org/ 10.1029/2010JE003692.

Krasnopolsky V A 1993 Photochemistry of the Martian atmosphere (mean conditions); Icarus 101 313-332.

Krasnopolsky V A 2006 Photochemistry of the Martian atmosphere: Seasonal, latitudinal, and diurnal variations; Icarus 185 153-170.

Lebonnois S, Qúemerais E, Montmessin F, Lefèvre F, Perrier S, Bertaux J-L and Forget F 2006 Vertical distribution of ozone on Mars as measured by SPICAM/Mars express using stellar occultations; J. Geophys. Res. Planets 111(E9), https://doi.org/10.1029/2005JE002643.

Lefèvre F, Lebonnois S, Montmessin F and Forget F 2004 Three-dimensional modeling of ozone on Mars; J. Geophys. Res. 109 E07004.

Lefèvre F, Bertaux J L, Clancy R T, Encrenaz T, Fast K, Forget F, Lebonnois S, Montmessin F and Perrier S 2008 Heterogeneous chemistry in the atmosphere of Mars; Nature 454(7207) 971-975, https://doi.org/10. 1038/nature07116.

Lemmon M T, Wolff M J, Bell J F III, Smith M D, Cantor B A and Smith P H 2015 Dust aerosol, clouds, and the atmospheric optical depth record over 5 Mars years of the Mars Exploration Rover mission; Icarus 251 96-111, https://doi.org/10.1016/j.icarus.2014.03.029.

Lindner B L 1988 Ozone on Mars: The effects of clouds and airborne dust; Planet. Space Sci. 36(2) 125-144.

Malicet J, Daumont D, Charbonnier J, Parisse C, Chakir A and Brion J 1995 Ozone UV spectroscopy. II. Absorption cross-sections and temperature dependence; J. Atmos. Chem. 21 263-273.

Martin L J and Zurek R W 1993 An analysis of the history of dust activity on Mars; J. Geophys. Res. 98 3221-3246.

Millour E, Forget F, Spiga A, Navarro T, Madeleine J B, Montabone L, Lefèvre F, Chaufray J Y, Lopez-Valverde M A, Gonzalez-Galindo F, Lewis S R, Read P L, Desjean
M C and Huot J P, MCD/GCM Development Team 2014 The Mars climate database (MCD version 5.1); LPI Contrib. 17911184.

Montabone L, Forget F, Millour E, Wilson R J, Lewis S R, Cantor B, Kass D, Kleinböhl A, Lemmon M T, Smith M D and Wolff M J 2015 Eight-year climatology of dust optical depth on Mars; Icarus 251 65-95, https://doi.org/ 10.1016/j.icarus.2014.12.034.

Montmessin F and Lefèvre F 2013 Transport-driven formation of a polar ozone layer on Mars; Nat. Geosci. 6(11) 930-933.

Nair H, Allen M, Anbar A D, Yung Y L and Clancy R T 1994 A photochemical model of the Martian atmosphere; Icarus 111(1) 124-150.

Navarro T, Madeleine J-B, Forget F, Spiga A, Millour E, Montmessin F and Määttänen A 2014 Global climate modeling of the Martian water cycle with improved microphysics and radiatively active water ice clouds; $J$. Geophys. Res. Planets 119 1479-1495.

Novak R E, Mumma M J, DiSanti M A, DelloRusso N and Magee-Sauer K 2002 Mapping of ozone and water in the atmosphere of Mars near the 1997 aphelion; Icarus 158 $14-23$.

Perrier S, Bertaux J-L, Lefèvre F, Lebonnois S, Korablev O, Fedorova A and Montmessin F 2006 Global distribution of total ozone on Mars from SPICAM/MEX UV measurements; J. Geophys. Res. Planets 111(E9), https:// doi.org/10.1029/2006JE002681.

Pincus R and Evans K F 2009 Computational cost and accuracy in calculating three-dimensional radiative transfer: Results for new implementations of Monte Carlo and SHDOM; J. Atmos. Sci. 66 3131-3146.

Serdyuchenko A, Gorshelev V, Weber M, Chehade W and Burrows J P 2014 High spectral resolution ozone absorption cross-sections - Part 2: Temperature dependence; Atmos. Meas. Tech. 7 625-636.

Sheel V and Haider S A 2016 Longterm variability of dust optical depths on Mars during MY24-MY32 and their impact on subtropical lower ionosphere: Climatology, modeling, and observations; J. Geophys. Res. Space Phys. 121 8038-8054, https://doi.org/10.1002/2015JA022300.

Smith M D 2009 THEMIS observations of Mars aerosol optical depth from 2002-2008; Icarus 202 444-452, https:// doi.org/10.1016/j.icarus.2009.03.027.

Smith M D, Wolff M J, Clancy R T and Murchie S L 2009 Compact reconnaissance imaging spectrometer observations of water vapor and carbon monoxide; $J$. Geophys. Res. 114 E00D03, https://doi.org/10.1029/ 2008JE003288.

Sneep M and Ubachs W 2005 Direct measurement of the Rayleigh scattering cross section in various gases; J. Quant. Spectrosc. Radiat. Transf. 92 293-310.

Thalman R, Zarzana K J, Tolbert M A and Volkamer R 2014 Rayleigh scattering cross-section measurements of nitrogen, argon, oxygen and air; J. Quant. Spectrosc. Radiat. Transf. 147 171-177.

Willame Y, Vandaele A C, Depiesse C, Lefèvre F, Letocart V, Gillotay D and Montmessin F 2017 Retrieving cloud, dust and ozone abundances in the Martian atmosphere using SPICAM/UV nadir spectra; Planet. Space Sci. 142 9-25. 
Wolff M J, Smith M D, Clancy R T, Arvidson R, Kahre M, Seelos F, Murchie S and Savijarvi H 2009 Wavelength dependence of dust aerosol single scattering albedo as observed by the compact reconnaissance imaging spectrometer; J. Geophys. Res. Planets 114(E2) E00D04.
Wolff M J, Clancy R T, Goguen J D, Malin M C and Cantor B A 2010 Ultraviolet dust aerosol properties as observed by MARCI; Icarus 208 143-155.

Zurek R W 1978 Solar heating of the Martian dusty atmosphere; Icarus 35 196-208.

Corresponding editor: Amit Kumar Patra 